\title{
Quantifying gas ebullition with echosounder: the role of methane transport by bubbles in a medium-sized lake
}

\author{
I. Ostrovsky ${ }^{*}$, D. F. McGinnis ${ }^{2}$, L. Lapidus ${ }^{1}$ and W. Eckert ${ }^{1}$ \\ ${ }^{1}$ Israel Oceanographic and Limnological Research, The Yigal Allon Kinneret Limnological Laboratory, P.O. Box 447, Migdal \\ 14950, Israel \\ ${ }^{2}$ Surface Waters-Research and Management, Swiss Federal Institute of Aquatic Science and Technology, Eawag, CH-6047 \\ Kastanienbaum, Switzerland
}

\begin{abstract}
In lakes and reservoirs with variable water level, gas ebullition can play a substantial role in methane transport in the water column and to the atmosphere. However, measuring methane ebullition from sediment is difficult as releases are highly heterogeneous and intermittent on macro- and micro-scales. In contrast to conventional gas traps and optical methods, hydroacoustic technology allows rapid scanning over large volumes of the water column synoptically to quantify gas bubble abundance. A 120-kHz dual beam downward-looking echosounder was used to measure the size distributions of bubbles that do not resonate at the sonar frequency. Data obtained with this sonar permit accurate calculation and evaluation of ebullition flux from the bottom. A robust relationship was established between gas volumes and backscattering cross-section of individual bubbles in experimental conditions, and rise velocities of bubbles were precisely measured. The volume backscattering coefficient was shown to be a good gauge of the total volume of bubbles per cubic meter of water, allowing the use of a single-beam sonar for measuring volumetric bubble concentrations. Data obtained from hydroacoustic surveys on Lake Kinneret, where gaseous methane is emitted from randomly dispersed sediment sources, indicated that $\sim 90 \%$ of bubbles escaping from soft sediments ranged from $1.3 \mathrm{~mm}$ to $4.5 \mathrm{~mm}$ and $~ 50 \%$ ranged from $2.0 \mathrm{~mm}$ to $3.2 \mathrm{~mm}$ in equivalent radius. In summer-fall 2001, the gaseous methane fluxes from hypolimnetic sediments was $\sim 10 \mathrm{mmol} \mathrm{m}^{-2} \mathrm{~d}^{-1}$, accounting for one-third of the observed methane accumulation in the hypolimnion. This relatively high ebullition rate could be attributed to the gradual decreasing of the mean water level in preceding years.
\end{abstract}

Ebullition is an important mechanism of gas liberation (e.g., methane, carbon dioxide, nitrogen) from bottom sediments to aquatic ecosystems and the atmosphere (Chanton and Whiting 1995; Leifer and Patro 2002; McGinnis et al. 2006). The emission of highly potent greenhouse gases has contributed to the increased atmospheric concentration of methane by approximately $1 \%$ per year over the last century

*E-mail: ostrovsky@ocean.org.il

\section{Acknowledgments}

We thank A. Wüest and M. Schmid from Eawag for helpful comments on earlier stages of manuscript preparation and B. Sulimani from the KLL IOLR for faithful technical assistance. We are grateful for the constructive criticism of three anonymous reviewers; their useful suggestions greatly improved the manuscript. We highly appreciate the administration and staff of the Sapir site of Mekorot (the Israeli National Water Company Ltd.) for logistical support and permission to use a large tank for our experiments. This study was supported by grants from the Israel Science Foundation (211/02 and 1011/05) and Swiss National Science Foundation (200021-112274).
(Rowland 1985). Point-source ebullition from shallow lakes is a dominant (and previously unrecognized) source of methane emission to the atmosphere. As lakes (especially in the northern hemisphere) are a prominent landscape feature, methane ebullition is a much larger and globally significant source of atmospheric methane than formerly thought (St. Louis et al. 2000; Bastviken et al. 2004; Walter et al. 2007).

Methane is produced in the sediment by anaerobic degradation of organic matter (Kiene 1991) and can reach the atmosphere in the dissolved or free gas phase by three pathways: turbulent diffusion, rising bubbles, or by advective transport through plant roots (Joyce and Jewell 2003). Among factors affecting the intensity of methane ebullition from the sediment is reduction of hydrostatic pressure due to decreasing water level, air pressure (Mattson and Likens 1987; Jakobsen et al. 1997; Dove et al. 1999), and tides (Martens and Klump 1980).

Because of large temporal and spatial variability of outgassing events (especially from point sources) in aquatic 
sediments (Quigley et al. 1999; Ostrovsky 2003; Walter et al. 2007), conventional methods (e.g., gas traps and video/photo techniques) cannot be used to adequately quantify gas emissions occurring in large areas (Asher and Farley 1995; Huttunen et al. 2001). Hydroacoustic technology, which allows the rapid scanning of large volumes of the water column, has a huge potential for the noninvasive appraisal of spatial heterogeneity of bubble concentrations in the water column (Vagle and Farmer 1992; Jackson et al. 1998; Ostrovsky 2003). However, acoustic methods typically lack the ability to resolve and classify individual targets. Therefore, quantification of specific targets (fish or bubbles) requires special consideration in the presence of other strong backscatterers (Rudstam and Johnson 1992; Ostrovsky 2003).

Because of the large density difference between water and rising bubbles, the latter are strong scatterers of acoustic energy. This permits the study of bubbles using scientific echosounders/sonars (Dando and Hovland 1992; Vagle and Farmer 1992). Bubble-size distribution in nature is a subject of great interest because many parameters required for the assessment of gas transport through the water column (e.g., rise velocity, gas exchange between bubble and water) are sizedependant (Wüest et al. 1992; Leifer and Patro 2002; McGinnis et al. 2004). To date, only a few attempts have been made to study spatial and temporal variability of gas emission with echosounders in the ocean (e.g., Greinert et al. 2003; Artemov 2006; Greinert et al. 2006); furthermore, there are almost no data reported from reservoirs and lakes (Ostrovsky 2003).

For quantification of bubble concentration in the water column and assessment of methane ebullition from the sediments, it is important to establish the relationship between acoustic size and bubble volume. This relationship is required to determine size-frequency distributions of bubbles in different water layers and to scale the backscattering strength from different strata in order to quantify the size-specific concentrations of bubbles (in terms of density and volume) and, finally, the outgassing intensity. Because the gas exchange rate between bubbles and water strongly depends on bubble size (Leifer and Patro 2002; McGinnis et al. 2006), information about size-specific density distribution of bubbles is essential for quantification of the fate of the emitted gases. Additionally, the scattering theory and comparison of bubble dimensions with the backscattering cross-section is not well established for bubbles that populate aquatic systems above soft sediments with resonant frequencies well below the frequency of the applied acoustic signal (Greinert and Nutzel 2004). Thus, the development of hydroacoustic methodology should promote an adequate assessment of methane ebullition from sediments, their fate in the ecosystem, and the potential for emission to the atmosphere.

The acoustic quantification of bubble release amounts from bottom sediments has broad applicability to the wide spectrum of hydroecological and biogeochemical studies. In particular, the method can be applied to study the effect of bubbling intensity on vertical transfer of particles, oil and gas blowouts, or $\mathrm{CO}_{2}$ sequestering. The limitations of active sonar have been widely discussed in literature as the method depends on the characteristics and properties of echo-reflecting objects and aquatic environment, where sound propagates, attenuates, and scatters (e.g., Urick 1975; Clay and Medwin 1977).

In this study, we use a downward-oriented dual-beam $120 \mathrm{kHz}$ echosounder to determine relationships between the volume of "non-resonant" bubbles (i.e., bubbles with resonant frequencies much smaller than the echosounder frequency), their backscattering cross-section, and rise velocity for experimental conditions. Then we deduced the relationship between volumetric concentration of bubbles in the water and volume backscattering coefficient and applied it to data collected on a freshwater, natural lake (Lake Kinneret, Israel) to investigate spatial variability in gas ebullition, quantify total methane flux from sediments, and demonstrate the role of ebullition on methane transport in the water column. Finally, we compare our measured results with bubble modeling and place into context Lake Kinneret as a methane source.

\section{Materials and procedures}

In this study, we used the same dual-beam (120 kHz) echosounder both in the laboratory experiments and field study, although a split-beam system would have also been suitable for this study. Acoustic calibration of the dual-beam echosounder using artificially produced gas bubbles was performed in an experimental setting under controlled conditions.

Laboratory setup-Measurements of backscattering crosssections and rise velocities of experimentally produced gas bubbles were carried out under controlled conditions in a large outdoor tank (diameter of $7 \mathrm{~m}$ and height of $4.5 \mathrm{~m}$ ) at the Sapir station of Mekorot, the Israeli National Water Company Ltd. The tank contained fresh Lake Kinneret water with water temperatures between $17^{\circ} \mathrm{C}$ and $21^{\circ} \mathrm{C}$. A customdesigned Bubble Measurement/Control System (BMCS) was deployed on the tank bottom and provided noninvasive time-resolved observations and controlled bubble size and rate of bubble release (Tassin and Nikitopoulos 1995; Boles et al. 2001). Backscattering cross-sections of the bubbles emitted at the base of BMCS were measured using a Biosonics dualbeam scientific echosounder DE5000 (6.5 ${ }^{\circ}$ half-power beam width). The acoustic transducer/receiver was mounted a few decimeters below the water surface and centered in a way that the acoustic axis was directed straight toward the bubble source. All cables and lines connecting the BMCS were positioned far away from the acoustic beam to avoid interference with the backscatter signal. The combination of the acoustic bubble size measurements with optical measurements and control of the bubble volume using the BMCS allowed us to correlate these parameters and estimate rise velocity for bubbles of specific volumes.

The BMCS includes several components: structural (support framework and housings), imaging (video, electronics, cables, 


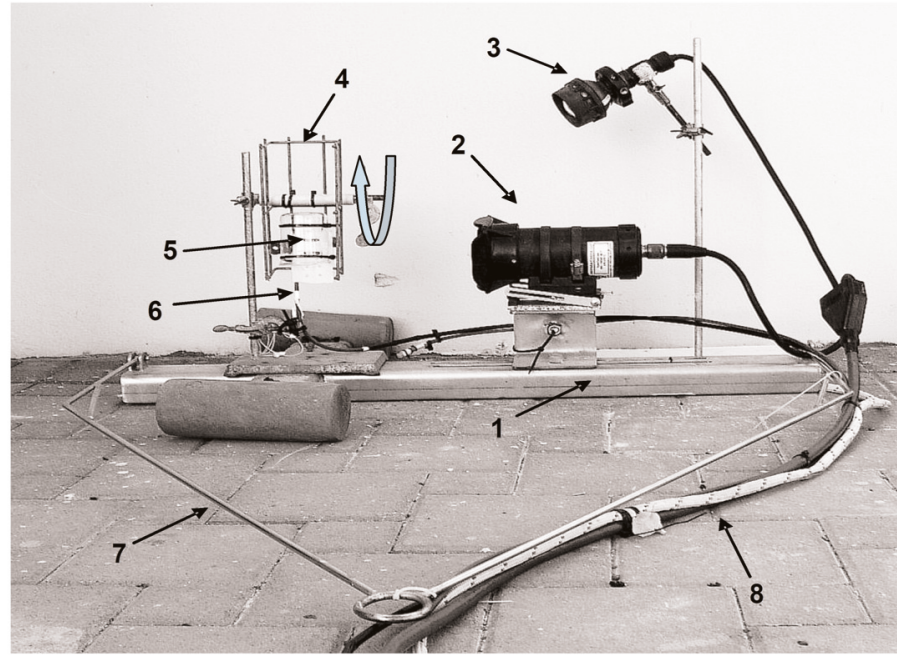

Fig. 1. Experimental setup: BMCS. 1, stainless steel platform; 2, video camera mounted on a movable chariot; 3 , source of light; 4 , rotating frame; 5 , volumetric beaker; 6 , outlet of the air tube (here needle/nozzle can be attached when rotating frame with beaker are removed); 7 , stainless steel frame (it allows for cables to be moved aside after deployment of the BMCS on the bottom; 8, cables (rope + electronic cable + highpressure air tube).

and optics), illumination (lights and diffusion screens), and data acquisition (equipment for recording and analysis of bubble images). The BMCS is shown schematically in Fig. 1. The structural framework consists of a stainless steel frame with vertical stands, and a moveable base that allows adjustment of the optical axis of the underwater video camera (DeepSea Power \& Light) to focus images of the needle/nozzle (or rotating beaker). The depth of field of the camera ranged from a few centimeters to infinity. Choosing bubble illumination at the proper angle ensured that in-focus bubbles appeared as rings with bright interiors. In our experiments, the video camera was positioned horizontally and allowed detecting and measuring bubbles at the moment of formation. The video signals were transmitted to the experimental station via an underwater cable that also served as the power supply for the unit. Video signals were recorded directly on a PC and were used to create digital movies of rising bubbles or rotating beakers. For a more detailed description of bubble observation and measurements using BMCS, see Leifer et al. (2003).

Acoustic considerations-The geometric size of a bubble should be proportional to its backscattering cross-section, assuming that the bubble has no resonance frequency close to the echosounder frequency (Clay and Medwin 1977). The resonance frequency $\left(\mathrm{f}_{\mathrm{R}}, \mathrm{kHz}\right)$ depends both on the bubble radius $(\mathrm{r}, \mathrm{mm})$ and the depth $(\mathrm{h}, \mathrm{m})$. An approximate expression for this relationship is $\mathrm{f}_{\mathrm{R}}=3.25\left(1+0.1 \mathrm{~h}\right.$ ) ${ }^{0.5} \mathrm{r}^{-1}$ (see the formulae in Urick 1975, p. 225). For instance, a $0.5 \mathrm{~mm}$ radius bubble resonates at a depth of $0 \mathrm{~m}$ at $6.5 \mathrm{kHz}$, while at a depth of $1000 \mathrm{~m}$, it resonates at $65 \mathrm{kHz}$. Bubbles are usually released from the bottom at radii larger than $1 \mathrm{~mm}$ (see discussion below), and our investigations of the relationship between bubble volume and acoustic size were limited to bubbles larger than $0.005 \mathrm{~mL}$ (equivalent radius $>1 \mathrm{~mm}$ ) with a $120 \mathrm{kHz}$ echosounder. With this frequency and depth range down to $44 \mathrm{~m}$ (maximum depth in Lake Kinneret), the resonant bubble radius is $<0.06 \mathrm{~mm}$.

It is useful to note that the higher the frequency of the echosounder, the shorter the obtainable range due to increased signal attenuation. However, high resolution measurements require high frequency (see Simmonds and MacLennan [2005] for practical considerations of the optimal sonar frequency). The sonar frequency of $120 \mathrm{kHz}$ is a midcompromise solution for a possible range of sonar frequencies of 70 to $200 \mathrm{kHz}$ for sampling small and medium targets (bubbles, fish) in lakes at water depths up to 50 to $100 \mathrm{~m}$, depending on signal-to-noise ratios. Due to practical reasons, our experiments were carried out using air bubbles. The effect of gas composition on acoustic properties of bubbles needs only to be considered for bubbles with dimensions much below $f_{R}$ (Clay and Medwin 1977). It was also shown experimentally that backscattering strengths of air and methane bubbles of nonresonance sizes are identical (Greinert and Nutzel 2004).

Lab experiments-Hydroacoustic experiments were carried out on air bubbles released at the bottom of the outdoor tank using two approaches:

(1) Small bubbles (volume up to $0.22 \mathrm{~mL}$ ) were emitted from vertically mounted syringe needles or larger nozzles with different internal diameters (e.g., $0.2 \mathrm{~mm}, 0.5 \mathrm{~mm}, 1.0 \mathrm{~mm}, 2.0 \mathrm{~mm}$, $4.0 \mathrm{~mm}$, etc.). All needles and nozzles were machined so that the internal edges were as sharp as possible, ensuring a constant contact radius for the forming bubble. Compressed and filtered air was supplied via a 6-mm (inner diameter) tubing from a SCUBA tank to the needle/nozzle mounted on the base of the BMCS. The stream of rising bubbles was controlled by a low-pressure gauge and fine-tuned with a needle valve. The interval between bubble formations was greater than $1 \mathrm{~s}$, so that the distance between rising bubbles was more than $25 \mathrm{~cm}$. Bubble dimensions (vertical and horizontal diameters) were measured at the moment of separation from the nozzle/needle. The error of optical measurement of bubbles dimensions did not exceed $6 \%$. The volume of the bubble was calculated based on bubble dimensions measured on the PC screen and a scaling factor, which was assessed by using the exact measure of the outer diameter of the nozzle/needle. With syringe needles, bubbles could be produced with the smallest volumes ( 0.005 to $0.016 \mathrm{~mL}$ ), while larger nozzles formed bigger bubbles ( 0.035 to $0.22 \mathrm{~mL}$ ).

(2) Large bubbles of precise volumes were produced using rotating volumetric beakers of various sizes. The graduated beaker was attached to the revolving frame, which was mounted on the BMCS (Fig. 1). The down-turned beaker was filled with filtered air to a target level. The filling process was observed with the underwater video camera. Upon reaching the required mark (specific volume), the beaker was quickly rotated by pulling the line attached to the revolving frame such that a large, single bubble (1 to $20 \mathrm{~mL}$ ) was released. 
Acoustic sizes of rising bubbles were measured using the downward-oriented Biosonics dual-beam echosounder operating at $120 \mathrm{kHz}$, a pulse width of $0.2 \mathrm{~ms}$, and a ping rate of 10 pings $\mathrm{s}^{-1}$. The acoustic system was calibrated with a standard target (Foote et al. 1987). The lower threshold for data collection was set to $-80 \mathrm{~dB}$. Data were collected between $0.5 \mathrm{~m}$ above the bottom to $1 \mathrm{~m}$ from the transducer $(\sim 1.2 \mathrm{~m}$ below the water surface). The data were processed with the Biosonics Visual Analyzer software. For detailed descriptions of the method used, see Ostrovsky (2003).

The acoustic size of a single bubble of specific volume is given as the backscattering cross-section, $\sigma_{\mathrm{bs}}$, or as its logarithmic equivalent, the target strength (TS), TS $=10 \log _{10}\left(\sigma_{\mathrm{bs}}\right)$. Because only single bubbles were released (the bubble formation at the tip of nozzles was controlled manually using realtime video), a single target filter may not be applied. Targets assessed at $>3 \mathrm{~dB}$ off the acoustic axis were rejected. The lower and upper $95 \%$ confidence limits of the mean $\sigma_{b s}$ were calculated and expressed as TS limits. For more details about hydroacoustic methods, the reader is referred to the literature (i.e., Urick 1975; Clay and Medwin 1977; Simmonds and MacLennan 2005).

The bubble volumes at the measurement depths were corrected for specific change in hydrostatic pressure incorporating Boyle's Law. The experiment with bubbles of a particular volume was repeated 20 to 30 times. Although the tests were carried out with air bubbles, the relationships obtained can be applied to bubbles formed with different gases because bubble $\sigma_{b s}$ depends on the density difference at the gas-water interface, which is nearly independent of gas composition for these test conditions.

Since the dual-beam or split-beam echosounders measure the position of the target in the water column, the rise velocities of bubbles can be determined. In our case, using an acoustic sampling rate of 10 pings $\mathrm{s}^{-1}$, bubble depth position was recorded about 30 to 60 times (depending on bubble size) within a $1.5-\mathrm{m}$ water stratum. This allowed for the precise calculation of rise velocity of the bubble as the slope of the depth versus ping number (time).

Field measurements - In Lake Kinneret, spatial changes in gas bubble abundance were quantified in 2001 using the same downward oriented echosounder, which was calibrated with a standard target of known target strength (see above). Data were collected in the summer when the lake was strongly stratified and gas bubbles were the only targets in the anoxic hypolimnion. For the locations of the 14 acoustic transects, see Ostrovsky and Walline (2001). The pulse width was set to 0.1 or $0.2 \mathrm{~ms}$, with a sampling rate of 5 pings $\mathrm{s}^{-1}$. The lower threshold for data collection was set to $-75 \mathrm{~dB}$. A minimum bottom-scattering strength of $-35 \mathrm{~dB}$ was chosen for bottom detection. Data were collected between $1 \mathrm{~m}$ from the transducer to $0.5 \mathrm{~m}$ above the bottom (maximum distance from the transducer was $38 \mathrm{~m}$ ).

Data were processed with the Biosonics Visual Analyzer software (version 4.02) to a vertical resolution of $1 \mathrm{~m}$. The program automatically compensates the received echo signals (voltage) depending on the range $(\mathrm{R}, \mathrm{m})$ of the target/layer by time-varied gain (TVG). A $40 \log _{10}(\mathrm{R})$ TVG is applied for the measurement of target size, while a $20 \log _{10}(\mathrm{R})$ TVG is applied when echo integrating. The dual-beam (or split-beam) echosounder allows accurately estimating $\sigma_{b s}$ of a single in situ target. To obtain accurate assessments of TS-frequency distribution, the Biosonics single target criteria were set as follows: (1) Pulses $<0.8$ and $>1.2$ than the transmission pulse length were excluded, (2) the minimal accepted correlation factor (i.e., the result of the correlation between shapes of the incident pulse and the echo pulse), as a criterion to eliminate multiple echoes was set to 0.96 . Targets with positions in the acoustic beam $>3$ $\mathrm{dB}$ off the acoustic axis, were also rejected. Target abundance is reported in terms of total number of targets within the $-70 \mathrm{~dB}$ to $-35 \mathrm{~dB}$ range and binned into $1 \mathrm{~dB}$ TS bins.

Acoustic data were collected in the anoxic strata, where bubbles were the only acoustic targets in water. In such zones bubbles rising from dispersedly distributed pointed sources are seen on echograms as target lines (chains) or solitary targets (Fig. 2). Acoustic returns were echo integrated to estimate the volumetric density of bubbles (see latter). The echo integration procedure was also applied to the data collected along transects to quantify lateral changes in volumetric density of targets near the bottom. For each transect, the volume backscattering coefficient, $\mathrm{s}_{v}$, was calculated in bins of 3-m width and 500-m horizontal length, defining four to six sampling units along each transect. The volumetric density of targets per cubic meter $(\mathrm{N})$ in each bin was estimated using the mean $\sigma_{b s}$ to scale the $s_{v}$, i.e., $\mathrm{n}=\mathrm{s}_{v} / \sigma_{\mathrm{bs}}$ (Simmonds and MacLennan 2005).

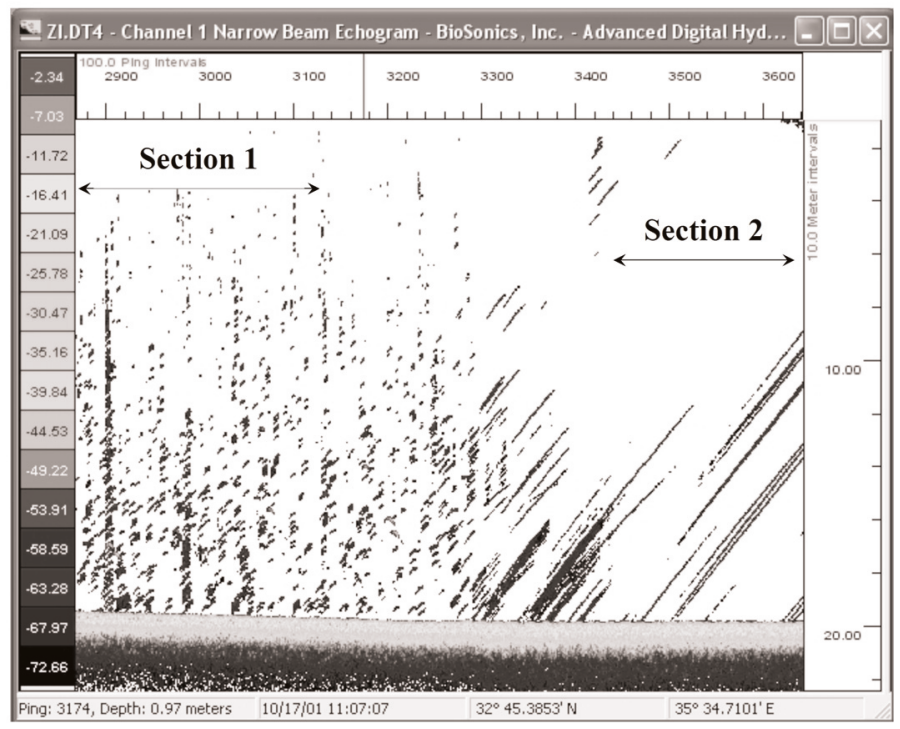

Fig. 2. Echogram shows bubble traces during acoustic survey in Lake Kinneret on 17 October 2001 (a 150-m section of a Zinebary transect). Majority of bubbles are in lines (segment 1$)$. At low boat speed $(\sim 0.4$ knots, section 2) rising bubbles are seen as diagonal lines. 


\section{Assessment}

In the following section, we first determine empiric relationships between gas volumes, acoustic sizes, and rise velocities of individual bubbles in laboratory conditions. We then apply this information to the lake to determine gaseous methane flux from the bottom.

Acoustic size of bubbles-The results of TS measurements of free-rising bubbles are presented on Fig. 3. With an increase in volume, the measured TS distribution of bubbles shifts to the right indicating a positive relationship between real and acoustically measured sizes. The dependence of the mean backscattering cross-section and bubble volume is shown in Fig. 4. For bubbles ranging from 0.005 to $20 \mathrm{~mL}$, the empiric relationship between $\sigma_{\mathrm{bs}}$ (in $\mathrm{m}^{2}$ ) and volume (in $\mathrm{mL}$ ) can be accurately described by a logarithmic equation $\left(\mathrm{r}^{2}=0.996, P<0.001\right)$ :

$$
\log \left(\sigma_{\mathrm{bs}}\right)=(0.745 \pm 0.013) \log (\mathrm{V})-(4.467 \pm 0.016)
$$

or

$$
\sigma_{\text {bs }}=3.40910^{-5} \mathrm{~V}^{0.745 \pm 0.013} \text {. }
$$

Taking into account the relationship between TS and $\sigma_{\mathrm{bs}}$, one can obtain the following equation:

$$
\mathrm{TS}=10 \log \left(\sigma_{\mathrm{bs}}\right)=7.45 \log (\mathrm{V})-44.67 .
$$

Equations 1 and 2 allow calculating the average acoustic size of bubbles of a specific volume. The accurate calculation of the mean bubble volumes from their $\sigma_{\mathrm{bs}}$ (or TS) can be done using the transformed forms Eqs. 1a and 2, as following

$$
\mathrm{V}=995600 \sigma_{\mathrm{bs}}{ }^{1.3426}
$$

and

$$
\mathrm{V}=995600 \mathrm{e}^{0.3092 \mathrm{Ts}} \text {. }
$$

Eqs. 1-4 can be used for calculation of the mean bubble volume in mixed-size populations from TS-frequency distributions.

Taking into account the relationship between TS and $\sigma_{\mathrm{bs}}$, it can be noted that the coefficient variation of $\sigma_{\mathrm{bs}}\left(\mathrm{CV}_{\sigma}\right)$ is proportional to the standard deviation of $\mathrm{TS}\left(\mathrm{SD}_{\mathrm{TS}}\right): \mathrm{SD}_{\mathrm{TS}} \approx 4.3 \mathrm{CV}_{\mathrm{\sigma}}$. In other words, $\mathrm{SD}_{\mathrm{TS}}$ is a measure of $\sigma_{\mathrm{bs}}$ variations. The standard deviation of smaller bubble $\mathrm{TS}\left(\mathrm{SD}_{\mathrm{TS}}\right)$, where volumes ranged from $0.005 \mathrm{~mL}$ to $0.1 \mathrm{~mL}$ (equivalent radius 1 to $3 \mathrm{~mm}$ ), gradually increased from 0.9 to $2.1 \mathrm{~dB}$. The greater variability in TS of larger bubbles in this range could not be associated with increased errors of measurements. On the contrary, the estimated relative errors were smaller for larger bubbles. With the further increase in bubble size, no apparent increase in $\mathrm{SD}_{\mathrm{TS}}$ was detected. These changes can be seen as changes in the widths of the vertical error bars on Fig. 4 .

Bubble allometry-The shape of rising bubbles varies with size. For smaller bubbles, surface tension dominates over stress from the rise, and they are nearly spherical. With increasing size, the surface tension force decreases, while the drag forces increase and as a result, larger bubbles are deformed from spherical to ellipsoidal (Clift et al. 1978; De Vries et al. 2002; Luther et al. 2004). To assess the deformation of rising bubbles in relation to their size, we consider an allometric relationship (i.e., the differential growth of the bubble dimensions) between bubble volume and backscattering cross-section measured with the down-looking echosounder. Despite the fact that the actual shapes of rising bubbles can be rather complex (Clift et al. 1978), one can describe the bubbles in the range of this study as elliptical (oblate spheroid). In this case, the bubble volume $(\mathrm{V})$ is $4 / 3 \pi \mathrm{r}_{\mathrm{h}}{ }^{2} \mathrm{r}_{\mathrm{v}}$, where $\mathrm{r}_{\mathrm{h}}$ and $\mathrm{r}_{\mathrm{v}}$ are the horizontal and vertical axis radii. The volume of the equivalent spherical bubble is $4 / 3 \pi r_{\text {eq }}{ }^{3}$, where $r_{\text {eq }}$ is equivalent radius $r_{e q}{ }^{3}=r_{h}{ }^{2} r_{v}$. The last parameter is widely used in literature describing gas bubbles and their behavior in the water column (Sam et al. 1996). The ratio of the horizontal radius to the vertical radius is an aspect ratio $\left(A R=r_{h} / r_{v}\right)$, which indicates how much a particular bubble is vertically flattened. AR can be also expressed in terms of $r_{h}$ and $r_{e q}$

$$
\mathrm{AR}=\mathrm{r}_{\mathrm{h}} \mathrm{r}_{\mathrm{v}}^{-1}=\mathrm{r}_{\mathrm{h}}\left(\mathrm{r}_{\mathrm{eq}}{ }^{-3} \mathrm{r}_{\mathrm{h}}{ }^{2}\right)=\mathrm{r}_{\mathrm{h}}{ }^{3} \mathrm{req}^{-3} .
$$

Assuming that $\sigma_{\mathrm{bs}}$ is proportional to the area of the horizontal cross section of an acoustic target (bubble projection to the plane perpendicular to acoustic beam), the square root of $\sigma_{b s}$ is a measure of $r_{h}$. Taking into account that $r_{h}{ }^{3} \sim \sigma_{b s}{ }^{3 / 2}$ and $\mathrm{r}_{\mathrm{eq}}{ }^{3} \sim \mathrm{V}$, AR can be expresses in terms of $\sigma_{\mathrm{bs}}$ and $\mathrm{V}$, i.e., directly measured variables:

$$
\mathrm{AR}=\mathrm{r}_{\mathrm{h}}{ }^{3} \mathrm{r}_{\mathrm{eq}}{ }^{-3} \sim \mathrm{\sigma}_{\mathrm{bs}}{ }^{3 / 2} \mathrm{~V}^{-1}=\mathrm{AR}^{\prime}
$$

where $A R^{\prime}$ is an estimate of the aspect ratio. If $\sigma_{b s}$ and $V$ are expressed in the same units (e.g., in $\mathrm{m}^{2}$ and $\mathrm{m}^{3}$, respectively), then $\mathrm{AR}^{\prime}$ is a nondimensional variable. Taking Eq. 1a into account, $\mathrm{AR}^{\prime}$ changes with bubble volume (in $\mathrm{mL}$ ), as follows

$$
\mathrm{AR}^{\prime}=\sigma_{\mathrm{bs}}^{3 / 2} \mathrm{~V}^{-1}=0.199 \mathrm{~V}^{0.117} .
$$

According to Eq. 7, the aspect ratio increases by a factor of 2.1 with bubble volume growth from 0.005 to $3 \mathrm{~mL}\left(\mathrm{r}_{\mathrm{eq}}\right.$ from $1 \mathrm{~mm}$ to $9 \mathrm{~mm}$ ), i.e., bubbles become progressively flattened. Our direct optical measurements of horizontal and vertical dimensions of rising $0.005 \mathrm{~mL}\left(\mathrm{r}_{\text {eq }}\right.$ is $\left.1 \mathrm{~mm}\right)$ bubbles showed that they are nearly spherical; while 0.1 to $3 \mathrm{~mL}$ ( $\mathrm{r}_{\text {eq }}$ from $3 \mathrm{~mm}$ to $9 \mathrm{~mm}$ ) bubbles are progressively compressed, with aspect ratios reaching on average $\sim 2$, some bubbles can have aspect ratios as large as 3.2 (Fig. 5). This agrees with findings of other authors (Luther et al. 2004; Guet et al. 2005): spherical shapes are typical for bubbles up to $r_{\text {eq }}=0.4 \mathrm{~mm}$, ellipsoidal up to $r_{\text {eq }}$ $=1.0 \mathrm{~mm}$, while bubbles of $\mathrm{r}_{\mathrm{eq}}>1.0 \mathrm{~mm}$ can have rather complex shapes (Fig. 5) because they experience surface oscillations upon ascent due to instabilities in the wake (Saffman 1956; Aybers and Tapucu 1969a; Aybers and Tapucu 1969b; Jamialahmadi et al. 1994; Leifer et al. 2000). An increase in oscillation and deformation of the echo-reflecting surface of bubbles also justifies the observed increase in $\sigma_{b s}$ variability with bubble volume. 

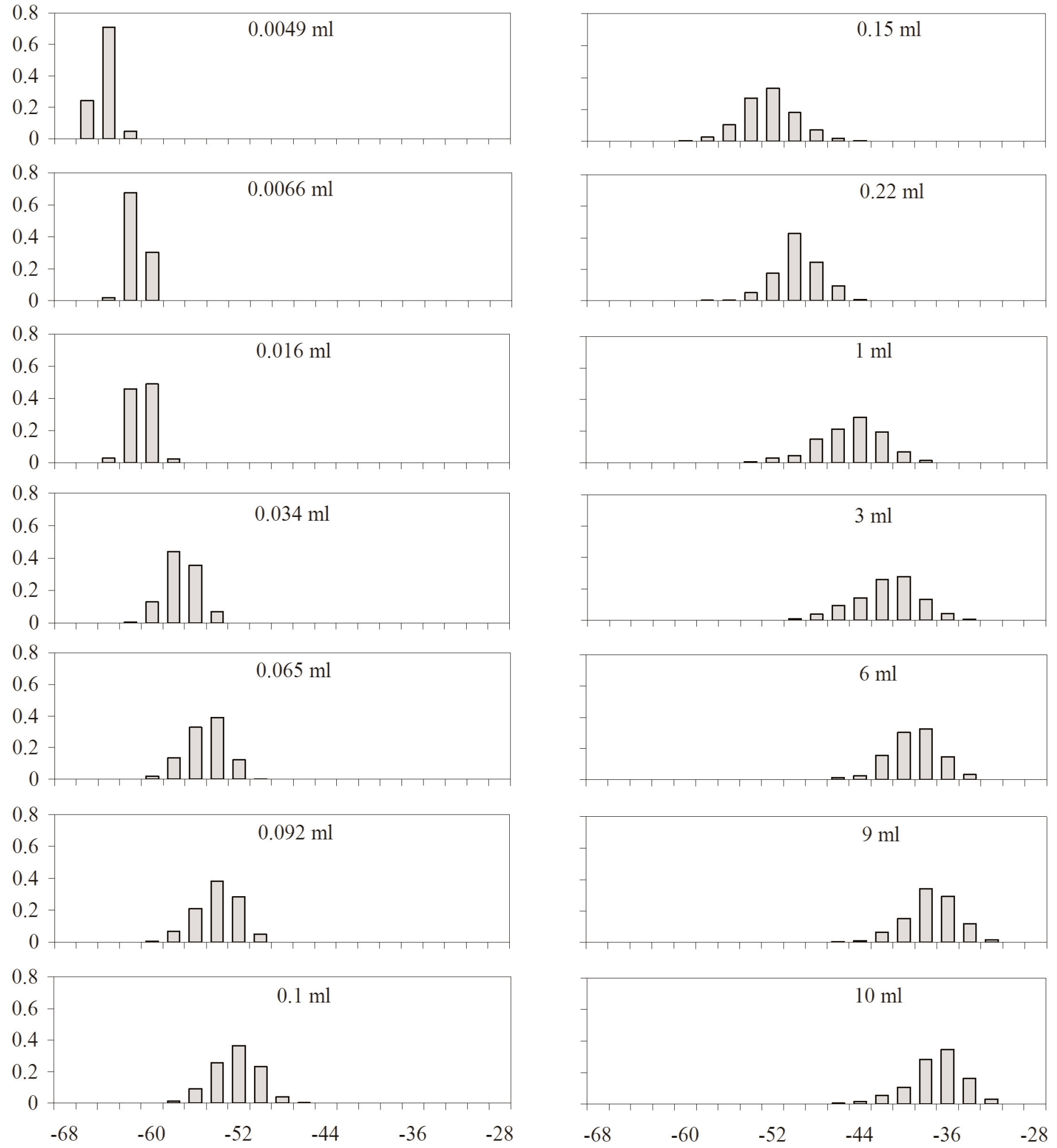

Target strength (dB)

Fig. 3. Target strength distribution for bubbles of different volumes. Total number of measured bubbles is taken as one. Each histogram was based on more than 240 measurements. 


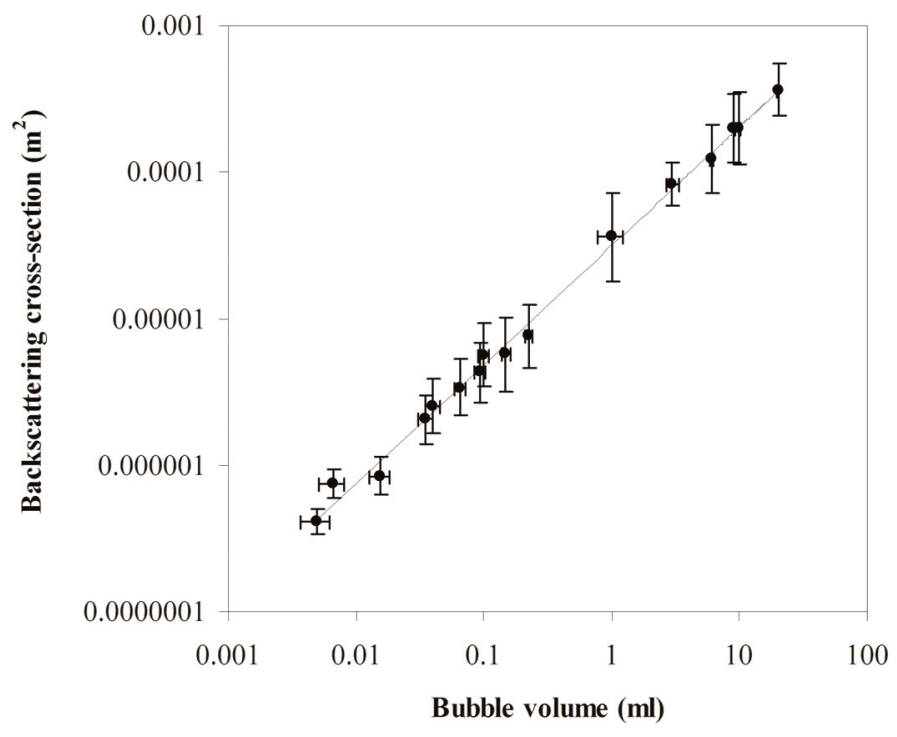

Fig. 4. Relationships between backscattering cross-section, $\sigma_{b s^{\prime}}$ and volume of bubbles. Each point represents the average $\sigma_{b s}$ for measured bubble volumes. Line represents best fit using liner regression of log transformed values (Eq. 1a). Bars represent means \pm SD.

An increase in aspect ratio with bubble size (Eq. 7) suggests that backscatter from flattened bubbles is notably stronger than from spherical ones of the same volume. To evaluate the effect of bubble shape on the $\sigma_{b s}-V$ relationship, one can also use Weston's (1967) model, which applies the ratio of actual bubble surface area to the equivalent surface area of a bubble of identical volume to adjust the $\sigma_{b s}$ calculated for a spherical bubble. This approach has been applied for the estimation of scattering response of nonspherical bubbles in sediments (Lyons et al. 1996; Anderson et al. 1998). Roughly assuming that bubbles of $r_{\text {eq }}=1 \mathrm{~mm}$ have an $\mathrm{AR}=1$ (sphere) and bubbles of $r_{\text {eq }}=9 \mathrm{~mm}$ have $\mathrm{AR}=2$ (oblate spheroid), the power index in Eq. 1 a can be estimated at 0.74 , i.e., higher than for bubbles with constant aspect ratios $(2 / 3 \approx 0.67)$. Thus, higher values of the power index can be explained by the observed changes in actual surface area of bubbles with size.

Rise velocity - The dependence of the rise velocities, $v\left(\mathrm{~m} \mathrm{~s}^{-1}\right)$, on bubble volume is shown in Fig. 6. The rise velocity of bubbles ranging from $0.005 \mathrm{~mL}$ to $0.035 \mathrm{~mL}$ decreases with increasing size, 0.035 to $0.22 \mathrm{~mL}$ bubbles have nearly constant velocity, while the rise velocity of bubbles larger than 0.5 to $1 \mathrm{~mL}$ increases with size. Since the rise velocity of larger bubbles $\left(v>0.37 \mathrm{~m} \mathrm{~s}^{-1}\right)$ is always higher than that of smaller ones, the obtained relationship can be used for predicting bubble volume of clean (uncontaminated), large bubbles from acoustically-measured rise velocities. Still, because the rise velocities of dirty (contaminated) bubbles can be notably lower than for clean ones (e.g., Leifer and Patro 2002), such estimates should be done with great caution. In the case of gas ebullition from the lake floor, where the majority of bubbles ranged from 1 to $4 \mathrm{~mm}$ in $\mathrm{r}_{\mathrm{eq}}$ (see below), the measurements of rise velocities do not allow correct assessment of bubble volume. For the entire range of the measured bubble volumes $(0.005$ to $20 \mathrm{~mL})$, the empiric relationship between $v$ (in $\mathrm{m} \mathrm{s}^{-1}$ ) and the logarithm of bubble volume $(\mathrm{V}$ in $\mathrm{mL}$ ) can be well described by the following equation $\left(\mathrm{r}^{2}=0.994, P<0.001\right)$ :

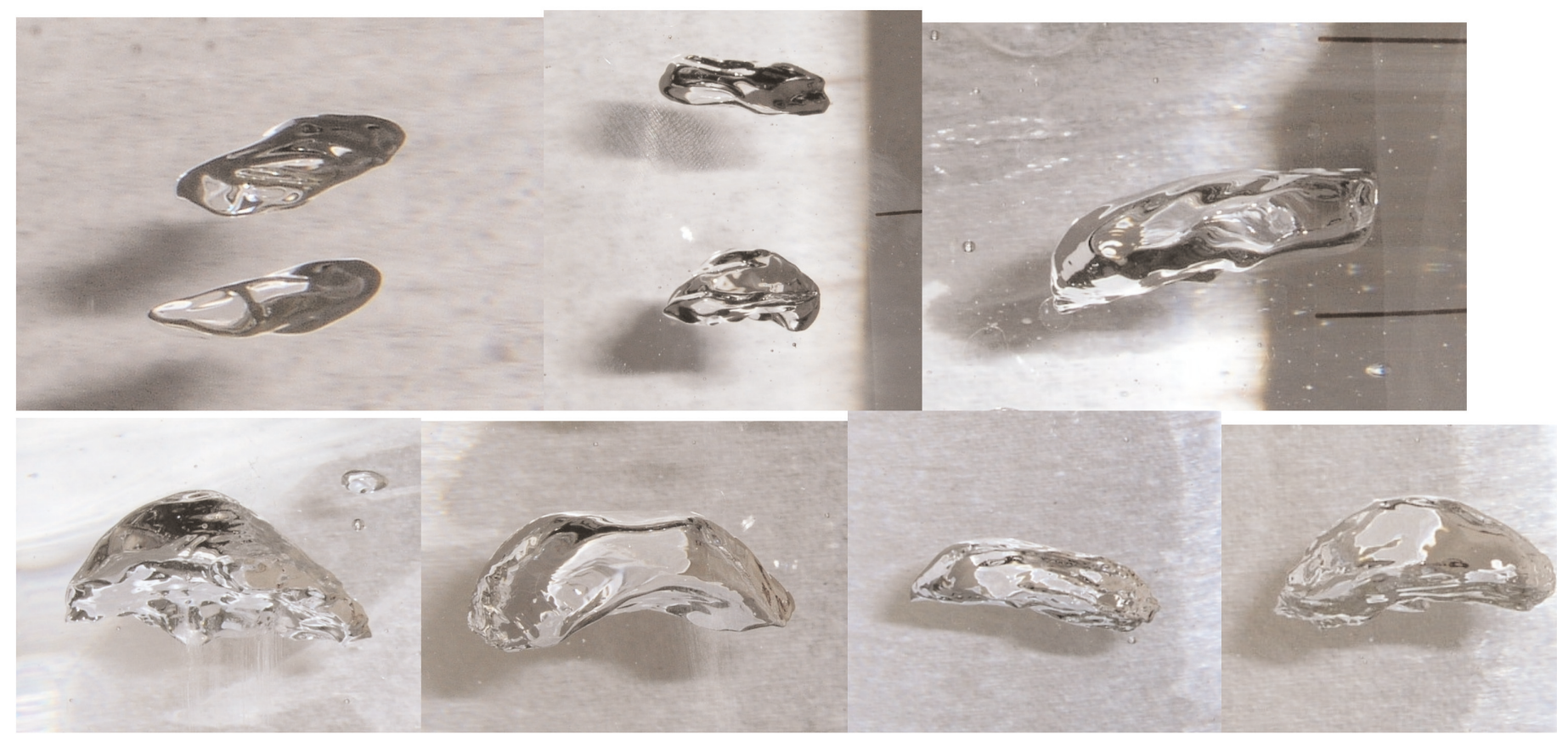

Fig. 5. Photo of rising bubbles of 1 to $3 \mathrm{~mL}$ demonstrating the variability in shape. 


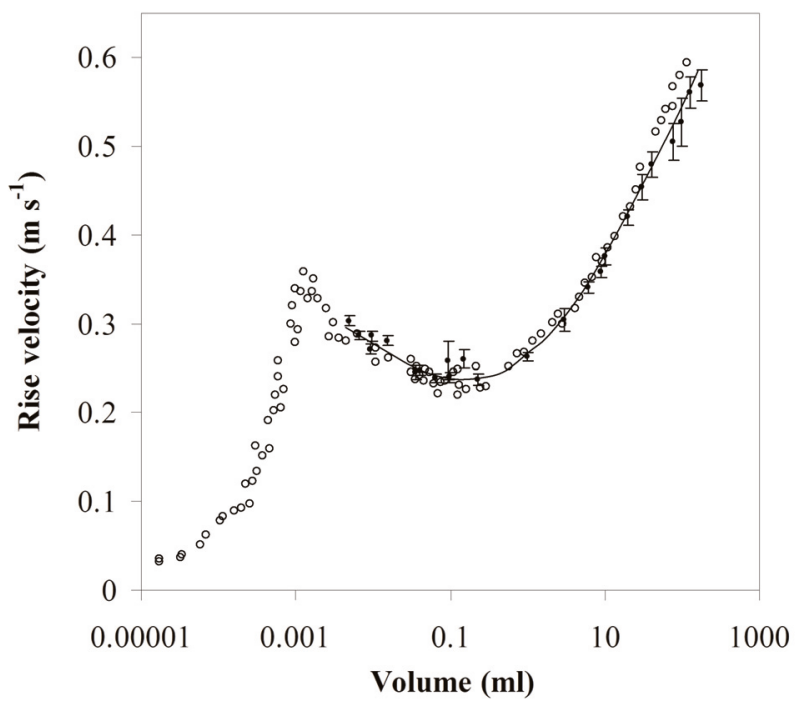

Fig. 6. Relationships between rise velocity and bubble volume. Filled circles are acoustic measurements at water temperature of $18.5 \pm 1.5^{\circ} \mathrm{C}$ (this study). Standard errors are shown as bars. Empty circles are data obtained for tap water at $20^{\circ} \mathrm{C}$ by Haberman and Morton (1954).

$$
\begin{gathered}
v=-(0.00219 \pm 0.00093)(\log V)^{4}-(0.000737 \pm 0.00091) \\
(\log V)^{3}+(0.04413 \pm 0.0050)(\log )^{2}+ \\
(0.0662 \pm 0.0034) \log \mathrm{V}+(0.2663 \pm 0.0050)
\end{gathered}
$$

The acoustic quantification of rise velocities perfectly matches the previous measurements by Haberman and Morton (1954). This suggests that the non-invasive acoustic method can be easily used for in situ assessments of bubble rise velocities.

Reconstruction of bubble size distribution in a lake-The reconstruction of bubble volume distribution was performed using a deconvolution algorithm for positive signals (e.g., Hovorka et al. 1998; Morhac and Matousek 2005) based on the TS-frequency distribution measured in nature and two transfer functions: (a) the TS-V relationship (Eq. 2) and (b) dispersion of the measured TS for bubbles of different sizes (Fig. 3). By applying the last function, we assumed that TS dispersions of bubbles in the experimental and natural conditions are the same. Still, if variability of TS in experimental conditions is greater than in the lake (e.g., due to errors of volume measurements), the reconstructed volume distribution will increase dispersion and vice versa. The results of deconvolution of the typical TS distributions of bubbles in the anoxic hypolimnion of Lake Kinneret in October 2001 (Ostrovsky 2003) suggest that distribution of bubble volumes can be approximated be a Gaussian function (Fig. 7). About $90 \%$ of the bubble volumes were between $0.1 \mathrm{~mL}$ and $0.38 \mathrm{~mL}$ (the respective $\mathrm{r}_{\text {eq }}$ varied from $1.3 \mathrm{~mm}$ to $4.5 \mathrm{~mm}$ ), while the average bubble volume was $0.097 \mathrm{~mL}$ $\left(\mathrm{r}_{\mathrm{eq}}=2.85 \mathrm{~mm}\right)$. The radii of about $50 \%$ of the bubbles were between $2.0 \mathrm{~mm}$ and $3.2 \mathrm{~mm}$. Optical measurements also showed that $r_{\text {eq }}$ of single methane bubbles or bubbles that form single streams vary between $1 \mathrm{~mm}$ and $4 \mathrm{~mm}(2-3 \mathrm{~mm}$, on average) in different aquatic ecosystems (e.g., Hornafius et al.

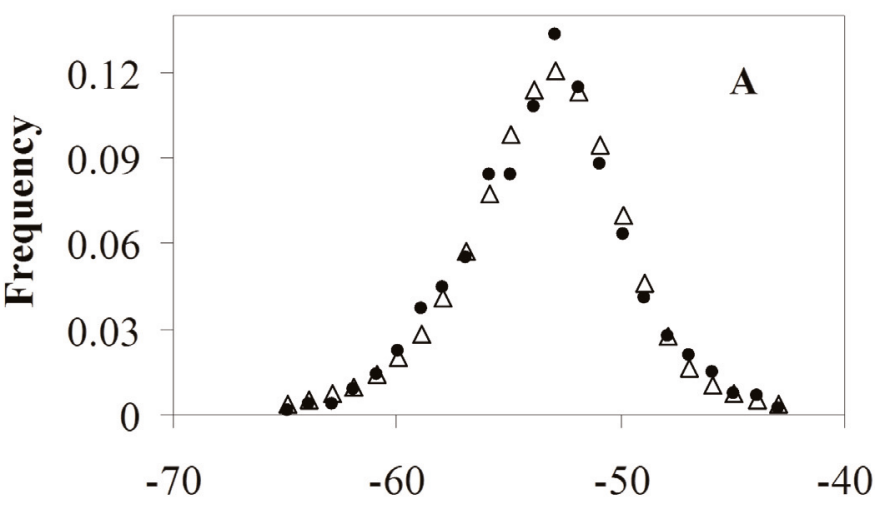

Target strength $(\mathrm{dB})$

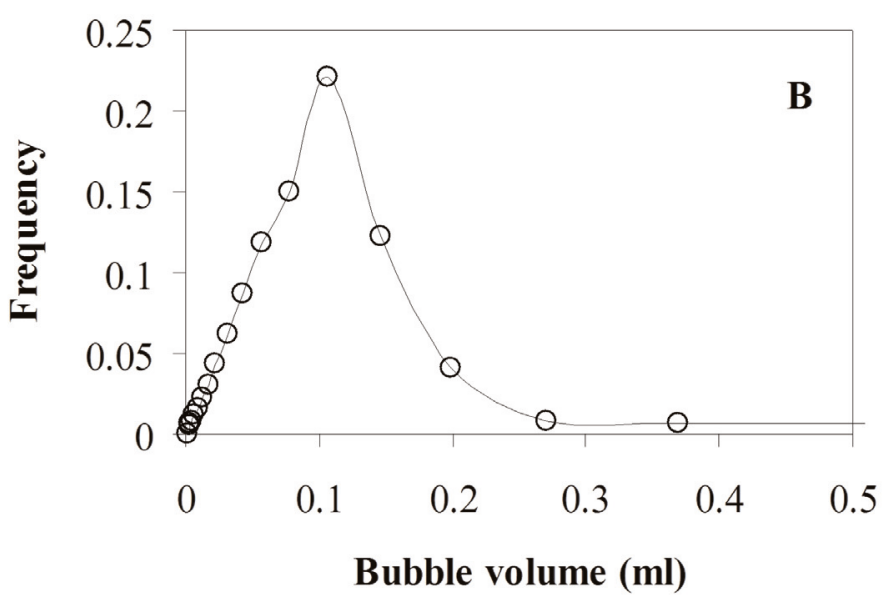

Fig. 7. Size distributions of bubbles in the hypolimnion of Lake Kinneret on 16 October 2001. Total number of bubbles is taken as one. (A) TS-frequency distributions. Filled circles, hydroacoustic data (Ostrovsky 2003). Empty triangles, back-calculated TS distribution (shown to demonstrate the adequacy of reconstruction of size distribution). (B) Volume-frequency distribution obtained using a deconvolution procedure (see explanations in the text).

1999; Leifer and Boles 2005). This is probably a universal size range of bubbles emitted from soft muddy sediments. The possible explanation of the steadiness of prevailing bubble sizes can be associated with the muddy sediment's ability to resist the increasing buoyant force as bubbles or gas pockets become larger. The critical bubble size should depend on sediment traits, such as porosity, specific density, adhesiveness, elasticity, bacterial matrix, etc. In unconsolidated sand/silt sediments, bubbles have spherical shapes and probably reach smaller maximum sizes (at which they can leave the sediments) than those in muddy cohesive sediments, where common bubble shape are eccentric oblate spheroids (Lyons et al. 1996; Best et al. 2004; Boudreau et al. 2005). This is supported by the finding that the mean TS of bubbles observed above the unconsolidated sediment (silt and sand) was notably smaller than above muddy sediments, while the upper TS edge was 


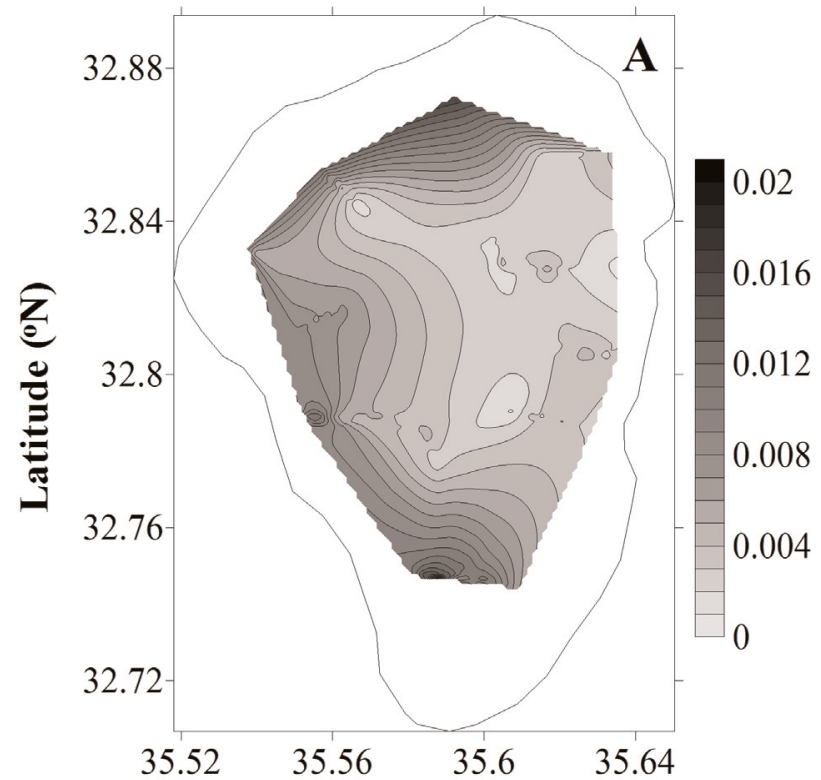

Longitude $\left({ }^{\circ} \mathrm{E}\right)$

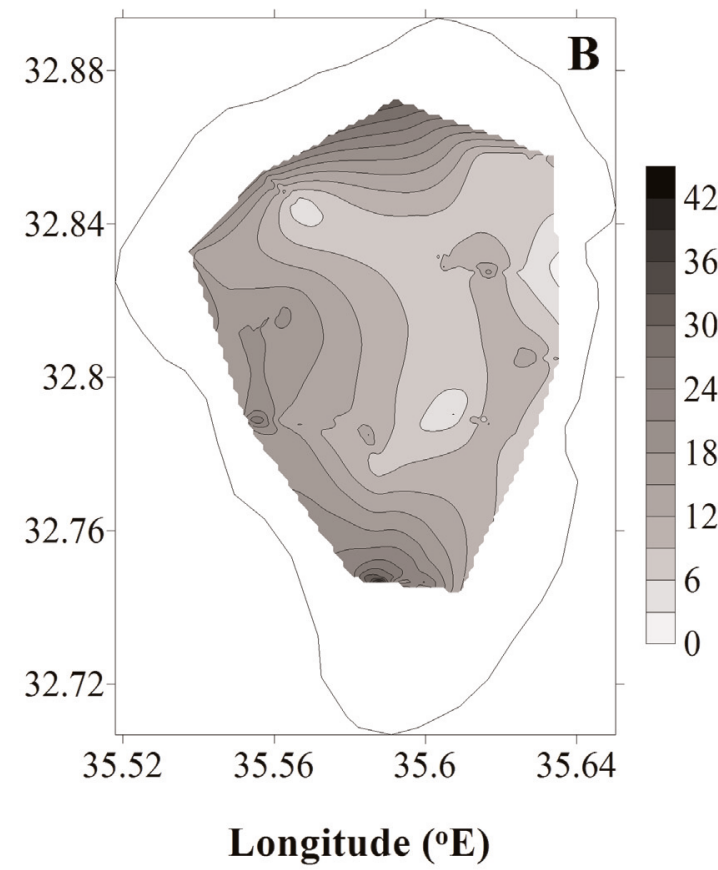

Fig. 8. Spatial variability in the volumetric concentration of bubbles $\left(\mathrm{mL} \mathrm{m}^{-3}\right)$ in the near-bottom water layer $(A)$ and gaseous methane flux $\left(m m o l ~ m{ }^{-2} d^{-1}\right)$ from the bottom (B) in Lake Kinneret on 2 August 2001.

about the same in both cases (Ostrovsky unpubl. data). Thus, specific traits of organic-rich muddy sediments, where methane production is usually high, should determine a size uniformity of liberated bubbles. A much broader range of bubble sizes was reported for high flow rate vent sites, where bubbles come out in a plume rather than in lines (Leifer and Boles 2005).

Quantification of bubble abundance-The volumetric concentration of bubbles in water, $\mathrm{V}_{\Sigma \mathrm{B}^{\prime}}\left(\mathrm{mL} \mathrm{m}^{-3}\right)$, is a product of bubble density, $\mathrm{N}$ (ind. bubbles $\mathrm{m}^{-3}$ ) and the average volume of bubbles, $\mathrm{V}(\mathrm{ml})$. Then, the $\mathrm{V}_{\Sigma \mathrm{B}}$ can be quantified as

$$
\mathrm{V}_{\mathrm{IB}}=\mathrm{NV}=\left(\mathrm{s}_{\mathrm{v}} \mathrm{\sigma}_{\mathrm{bs}}{ }^{-1}\right)\left(995600 \mathrm{\sigma}_{\mathrm{bs}}{ }^{1.3426}\right)=542100 \mathrm{~s}_{\mathrm{v}} \mathrm{\sigma}_{\mathrm{bs}}{ }^{0.3426} \text {. }
$$

According to Eq. 9, the volumetric concentration of bubbles should be proportional to $s_{v} \sigma_{\mathrm{bs}}{ }^{0.3426}$. The latter implies the necessity to evaluate both variables $\left(\mathrm{s}_{v}\right.$ and $\left.\sigma_{\mathrm{bs}}\right)$, which can be done accurately with dual beam or split beam echosounders. The mean TSs of methane bubbles released from the muddy bottom varied in Lake Kinneret between $-57 \mathrm{~dB}$ and $-53 \mathrm{~dB}$ (Ostrovsky 2003). These limits correspond to the rather narrow variations in $\sigma_{\mathrm{bs}}{ }^{0.3426}$ of 0.0111 to 0.0153 . Substituting the average $\sigma_{\mathrm{bs}}{ }^{1.3426}=0.0135$ to Eq. 9 , one can obtain the formulae for a good approximation of $\mathrm{V}_{\Sigma \mathrm{B}}$ solely based on $\mathrm{s}_{v}$

$$
\mathrm{V}_{\Sigma \mathrm{B}} \approx 13500 \mathrm{~s}_{v} \text {. }
$$

The low variability in the mean $\sigma_{b s}$ allows using a simplified Eq. 10 that relates $V_{\Sigma B}$ and $s_{v}$. In this case, the directly measured $s_{v}$ can be simply converted to the volumetric concentration of bubbles even if bubble dimensions are not well defined. This presumes that a single-beam echosounder can be also used for quan- tification of the total volume of bubbles in the water column in the cases where sizes of bubbles do not vary much, i.e., in areas where single bubbles or dispersed bubble streams rising from soft sediments are dominate. Our results agree with the conclusions of Greinert and Nutzel (2004), who performed experiments with a horizontal-looking sonar and showed that the backscattering strengths of artificially produced bubble streams correlated well with bubble flux rate. It was also suggested that for bubbles with sizes large enough to resonate at sonar frequency, the mean size of the emitted bubbles did not affect the correlation.

Gaseous methane flux: a Lake Kinneret case-Equation 10 permits us to calculate the gaseous methane flux, $\mathrm{F}\left(\mathrm{mmol} \mathrm{m}^{-2} \mathrm{~d}^{-1}\right)$, from Lake Kinneret bottom sediments taking into account the average rise velocity of bubbles $\left(0.22 \mathrm{~m} \mathrm{~s}^{-1}\right.$; Ostrovsky 2003), the proportion of methane in the gas emitted from the bottom (ca. 90\%, Eckert unpubl. data), gas pressure at the bottom, and the compressibility of gases (Duan et al. 1992). The spatial distributions of the near-bottom $V_{\Sigma B}$ and $F$ were plotted based on a hydroacoustic survey carried out on 2 August 2001 (Fig. 8). In the northern, western, and southern parts of Lake Kinneret, where the bottom slope is more gentle $\left(0.2^{\circ}\right.$ to $\left.0.4^{\circ}\right)$, the highest near-bottom bubble concentrations were detected above the shallowest areas of the hypolimnion (16 m to $20 \mathrm{~m}$ depth). On the contrary, in the eastern part of the lake where the bottom slope is much steeper $\left(>0.8^{\circ}\right)$, the highest concentrations of bubbles were found in deeper areas ( $25 \mathrm{~m}$ to 30 $\mathrm{m}$ depths). The difference is attributed to areas where organicrich sediments are accumulated in high concentrations (Ostrovsky and Yacobi 1999; Yacobi et al. 2000). In the regions 
$>34 \mathrm{~m}$ depth, the lake-average concentration of bubbles $\left(0.0043 \pm 0.0007 \mathrm{~mL} \mathrm{~m}^{-3}\right)$ was about 1.7 times higher than that in the depth range of 22 to $24 \mathrm{~m}\left(0.0025 \pm 0.0004 \mathrm{~mL} \mathrm{~m}^{-3}\right)$. However, the methane fluxes from the bottom in these regions were rather similar $\left(10.9 \pm 1.8 \mathrm{mmol} \mathrm{m}^{-2} \mathrm{~d}^{-1}\right.$ and $8.9 \pm$ $1.5 \mathrm{mmol} \mathrm{m}^{-2} \mathrm{~d}^{-1}$, respectively), which reflects the similarity in rates of methane production below $22 \mathrm{~m}$.

\section{Discussion}

Here, we discuss the potential of the acoustic method to quantify the bubble flux in natural water bodies, where gas emission events have large spatial and temporal heterogeneity. We also argue the method's practical applicability and limitations.

Bubble sizes-The fate of methane released from the sediment in bubbles strongly depends on the initial bubble size. Larger bubbles have a greater volume, rise more rapidly, have lower surface-to-volume ratios, lower specific rate of gas exchange between the bubble and surrounding water, and thus transport methane much higher in the water column than smaller bubbles (Leifer and Judd 2002; Leifer and Patro 2002; McGinnis et al. 2006).

The observed TS range of bubbles in the water column fully overlapped with TS range of fish in Lake Kinneret (Walline et al. 1992; Horne et al. 2000). This implies that all hydroacoustic methods (and their limitations), which have been established for assessment of fish size spectrum and abundance (e.g., Kieser et al. 2005; Simmonds and MacLennan 2005), can also be applicable for quantification of bubbles rising from the sediments. On the other hand, similarity of the acoustic sizes of fish and bubbles may require the elaboration of special approaches for hydroacoustic differentiation of both types of targets in the water column.

The change in size of rising methane bubbles in Lake Kinneret can be accurately predicted by a discrete-bubble model (McGinnis et al. 2006). Bubbles of typical size range (3 to $10 \mathrm{~mm}$ in diameter, see above) emitted from the greatest (44 m) depth decrease in volume until a certain minimum at some intermediate depth and then begin to expand. For instance, a 3-mm bubble emitted at $44 \mathrm{~m}$ depth first decreases its diameter to $1.1 \mathrm{~mm}$ at $8 \mathrm{~m}$ and then increases to $1.3 \mathrm{~mm}$ at the water surface. The minimal size of such a bubble is still much larger than the diameter of a resonating bubble at $120 \mathrm{kHz}$ sound frequency $(0.06 \mathrm{~mm}$, see above). This suggests that bubbles populated in the lake could not resonate at sonar frequency, such that the developed Eqs. 1-4 and 9-10 can be applied to the entire water column. A 6.0-mm diameter bubble released at $44 \mathrm{~m}$ depth should reach its minimal diameter of $5.3 \mathrm{~mm}$ at $21 \mathrm{~m}$ depth and then expand to $6.5 \mathrm{~mm}$ at the surface. This result agrees well with the observation of the changes of the mean TS of bubbles with depth in Lake Kinneret reported earlier (Ostrovsky 2003).

Bubble allometry-Geometric sizes $\left(\mathrm{r}_{\mathrm{eq}}\right)$ of bubbles, which are not at resonance at the applied sound frequency, can be assessed based on $\sigma_{b s}$ assuming that bubble scatter is omnidi- rectional (Clay and Medwin 1977; Ostrovsky 2003). This postulation is suitable for spherical bubbles. Still, because bubbles escaping from the sediment are large enough and thus have nonspherical shapes (Saffman 1956; Aybers and Tapucu 1969b; Clift et al. 1978; Jamialahmadi et al. 1994), the relation between geometric and acoustic sizes can be obtained if sizespecific patterns of bubble scatter are known. In this paper, we determined an empirical relationship between the volume of "non-resonant" bubbles and $\sigma_{b s}$ measured with a down-looking $120 \mathrm{kHz}$ echosounder. This relationship shows that $\sigma_{\mathrm{bs}}$ is proportional to $\mathrm{V}^{0.745}$, which also suggests an allometric change in bubble shape with size: larger bubbles became more flattened. Because of shape, the measured $\sigma_{\mathrm{bs}}$ of flattened bubbles should depend on their angular positions relative to the acoustic axis of the sound-beam orientation. This should be taken into account when data collected with differently oriented (e.g., horizontal -looking and down-looking) acoustic systems are compared. It is important to stress that despite the fact that Eq. 1 covers the entire range of bubble sizes found in Lake Kinneret, it cannot be unquestionably used for computation of volumes of bubbles when sizes fall out of the range of definition, or for bubbles that can be found at greater depths where they become resonant with the sonar frequency.

Bubble rise velocity - The bubble rise velocity, which is necessary for the calculation of the gaseous methane flux from sediments, strongly depends on bubble size and purity of the bubble surface. In particular, bubbles polluted with surfactants can have much lower rise velocities than clean ones (Vasconcelos et al. 2003; Leifer and Wilson 2004). Also contamination of the bubble surface restricts gas exchange between the bubble and water (Johnson and Wangersky 1987; Thorpe et al. 1992), which can increase the proportion of methane transported to the atmosphere. Therefore, the actual rates of bubble ascents are necessary for in-situ measurements. The rise velocities obtained in our experiments using an echosounder technique nearly perfectly fit the results obtained by other authors (i.e., Haberman and Morton 1954). The accurate assessment of rise velocities using the acoustic method is important for the practical implementation of this method in natural waters where contaminated (i.e., oil-coated) or hydrate-coated bubbles may have different rise velocities (Leifer and Patro 2002; McGinnis et al. 2006). Accurate acoustic estimates of bubble rise velocity, for instance, can be used to evaluate gas fluxes from natural gas seeps on the continental shelf or for studying the performance of bubble-diffusers used for hypolimnetic oxygenation or destratification of lakes and reservoirs (McGinnis et al. 2004).

Volumetric estimates-Spatial heterogeneities of gas ebullition in areas of hydrocarbon seeps were studied using sonar techniques (Vagle and Farmer 1992; Jackson et al. 1998; Quigley et al. 1999; Greinert et al. 2006), assuming the direct relationship between backscattering strength and the amount of bubbles in the water column. In fact, our data (Eq. 10) showed that the backscattering strengths of bubble popula- 


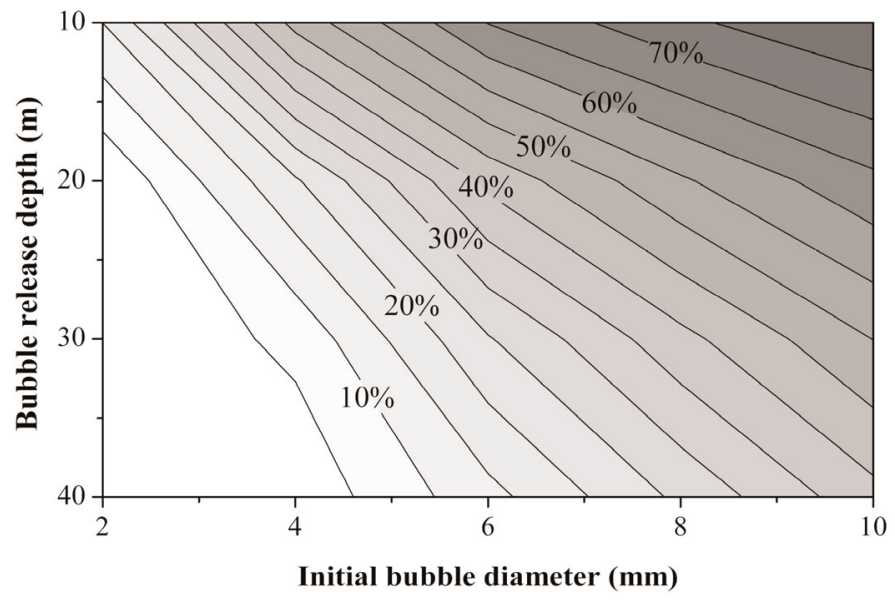

Fig. 9. Contour plot developed from bubble model of McGinnis et al. (2006) indicating the percentage of the initial methane mass reaching the atmosphere as a function of initial bubble diameter and release depth (methane reaching the surface is read at the point where the bubble diameter and release depth intersect on the plot). Environmental conditions were those from Lake Kinneret.

tion correlate well with the total volume of bubbles in the water column, at least in the cases where sizes of bubbles do not vary much (e.g., in areas where single bubbles or dispersed bubble streams rising from soft sediments are dominate). For gas vents where a broad distribution of bubble sizes exist (Leifer and Judd 2002; Leifer and Boles 2005), the dual(or split-beam) sonar is required for accurate assessment of the mean $\sigma_{\text {bs }}$ (see Eq. 9). Still, the applicability of the obtained formulas to the dense bubble vents or seeps should be specially evaluated in further studies by calibration of the measured $s_{v}$ versus known volumetric density of bubbles in artificial bubble plumes, when the mean size of bubbles is known.

When acoustic targets have a very high concentration (e.g., fish in dense schools, bubbles in plumes), impediment of acoustic methods can be due to shadowing effect (e.g., Clay and Medwin 1977). This can restrict to a certain extent the application of direct hydroacoustic measurements of bubbles in a very dense plume. Still, even in this case, indirect methods can be implemented to tackle the problem with hydroacoustic surveys (e.g., extrapolation of changes in $s_{v}$ with range can be implemented for the homogenous medium). A preliminary attempt to evaluate volumetric concentrations of gas in dense bubble plumes (a hypolimnetic air diffuser of known flow rates was used for groundtruthing) suggested that a $120 \mathrm{kHz}$ echosounder can be applied to such cases when the average concentration of bubbles in the upper $25 \mathrm{~m}$ layer was below $40 \mathrm{~mL} \mathrm{~m}^{-3}$ (Ostrovsky and McGinnis, unpublished data). Such high bubble densities can be found only in very extreme situations (e.g., intense gas seepage, outbursts, or gas aerators operating at relatively high flow rates). Therefore, this restriction can possibly be disregarded for quantification of gaseous methane fluxes in most lakes and reservoirs of moderate depths.
Method applicability-Application of the hydroacoustic approach to Lake Kinneret measurements resulted in the gaseous methane fluxes from sediments located between 22 to $39 \mathrm{~m}$ depths of $\sim 10 \mathrm{mmol} \mathrm{m}^{-2} \mathrm{~d}^{-1}$ in August 2001. This amount was close to the seasonal (June-December 2001) average (Ostrovsky unpubl. data). Such a profound release of gaseous methane was apparently related with a long-term water level decrease since 1993. The mean methane flux from the bottom can be also assessed based on accumulation rates of dissolved methane in the water column (mainly in the anoxic hypolimnion). The respective measurements carried out in 1998-2000 (data by Werner and Conrad 2007) suggested that the average methane flux from the sediment for the period from June to November was about $\sim 12 \mathrm{mmol} \mathrm{m}^{-2}$ $\mathrm{d}^{-1}$. Part of the methane accumulated in the water column could be attributed to the methane diffusion from the sediments, while other contribution is due to dissolution from the rising bubbles (methane consumption in the anoxic hypolimnion can be neglected). Using the bubble model of McGinnis et al. (2006), we are able to estimate the percent methane reaching the atmosphere. For a pure methane bubble, Fig. 9 shows the relationship between bubble release depths, initial bubble size, and amount ultimately reaching the atmosphere. Taking into account the bubble dissolution pattern (Fig. 10) and Lake Kinneret bathymetry, 43\% of the gaseous methane released as $3 \mathrm{~mm}$ (in radius) bubbles from the deep sediments ( $>20 \mathrm{~m}$ isobath) should be dissolved within the hypolimnion (i.e., up to $15 \mathrm{~m}$ isobath), while $32 \%$ of the gaseous methane released as bubbles reached the atmosphere. Assuming that in 2001 the dynamics of dissolved

\section{Losses within the water column (\%)}

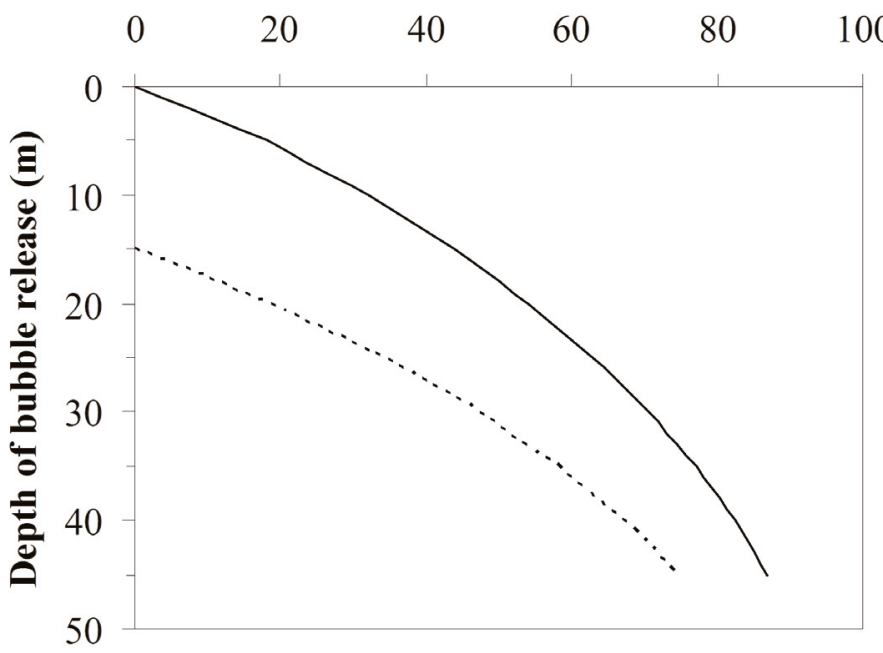

Fig. 10. Losses of methane from bubbles released from different depths. The solid line represents losses within the entire water column, and the dotted line represents losses within the hypolimnion (thermocline position is at $15 \mathrm{~m}$ depth). Calculations were done based on gas exchange model (McGinnis et al. 2006) applied to $3 \mathrm{~mm}$ (in radius) bubbles. 
methane in the lake was similar to that in previous years, it is estimated that bubbles could contribute $\sim 36 \%$ to the total methane accumulation in the hypolimnion. This estimate shows that in lakes (or reservoirs) with declining water levels, bubbles can play an essential role in methane evolution in the anoxic hypolimnion and in direct methane transfer to the atmosphere. Thus, lakes and reservoirs with varying water levels could be a substantial greenhouse source.

Overall, quantification of gaseous methane emission from the bottom is a rather complex task due to large spatial and temporal variability of the gas emission events. As a result, there is a gap in knowledge regarding the contribution of gas ebullition to the total methane flux from sediments in shallow lakes and reservoirs. However, this information is necessary to determine what portion of deposited organic carbon is used by methanogenic bacteria, to evaluate the fate of bubbles in the water column, and to quantify the amount of methane that ultimately reaches the atmosphere. The authors believe that the suggested method, in the current state of its development, can be safely and reliably applied for quantification of gaseous methane fluxes in lakes/reservoirs with depth-ranges similar to Lake Kinneret (up to $\sim 100$ to $150 \mathrm{~m}$ deep when $120 \mathrm{kHz}$ sonar is used). This method could also be applied to shallow ocean seep sites were fluxes are moderate. The further development of hydroacoustic methods is required for assessment of gas emission from deep sediments and from dense seeps.

\section{References}

Anderson, A. L., F. Abegg, J. A. Hawkins, M. E. Duncan, and A. P. Lyons. 1998. Bubble populations and acoustic interaction with the gassy floor of Eckernforde Bay. Cont. Shelf Res. 18:1807-1838.

Artemov, Y. G. 2006. Software support for investigation of natural methane seeps by hydroacoustic method. Mar. Ecol. J. 5:57-71.

Asher, W. E., and P. J. Farley. 1995. Phase-Doppler anemometer measurement of bubble concentrations in laboratorysimulated breaking waves. J. Geophys. Res. 100:7045-7056.

Aybers, N. M., and A. Tapucu. 1969a. The motion of gas bubbles rising through stagnant liquid. Wärme Stoffübertrag 2:118-128.

and $1969 \mathrm{~b}$. Studies on the drag and shape of gas bubbles rising through a stagnant liquid. Wärme Stoffübertrag 2:171-177.

Bastviken, D., J. Cole, M. Pace, and L. Tranvik. 2004. Methane emissions from lakes: Dependence of lake characteristics, two regional assessments, and a global estimate. Global Biogeochem. Cycles 18:GB4009 doi: 4010.1029/ 2004 GB002238.

Best, A. I., M. D. J. Tuffin, J. K. Dix, and J. M. Bull. 2004. Tidal height and frequency dependence of acoustic velocity and attenuation in shallow gassy marine sediments. J. Geophys. Res. 109:B08101 doi: 10.1029/2003JB002748.
Boles, J. R., J. F. Clark, I. Leifer, and L. Washburn. 2001. Temporal variation in natural methane seep rate due to tides, Coal Oil Point area, California. J. Geophys. Res. 106:2707727086.

Boudreau, B. P., and others. 2005. Bubble growth and rise in soft sediments. Geology 33:517-520.

Chanton, J. P., and G. J. Whiting. 1995. Trace gas exchange in freshwater and coastal marine environments: ebullition and transport by plants, p. 98-125. In P. A. Matson and R. C. Harriss [eds.], Biogenic trace gases: Measuring emissions from soil and water. Blackwell Science.

Clay, C. S., and H. Medwin. 1977. Acoustical oceanography: Principles and applications. Wiley.

Clift, R., J. R. Grace, and M. E. Weber. 1978. Bubbles, drops and particles. Academic Press.

Dando, P. R., and M. Hovland. 1992. Environmental-effects of submarine seeping natural-gas. Cont. Shelf Res. 12:1197-1207.

De Vries, J., S. Luther, and D. Lohse. 2002. Induced bubble shape oscillations and their impact on the rise velocity. Eur. Phys. J. B 29:503-509.

Dove, A., N. Roulet, P. Crill, J. Chanton, and R. Bourbonniere. 1999. Methane dynamics of a northern boreal beaver pond. Ecoscience 6:577-586.

Duan, Z., N. Moller, and J. H. Weare. 1992. An equation of state for the CH4-CO2- $\mathrm{H} 2 \mathrm{O}$ system: I. Pure systems from 0 to $1000^{\circ} \mathrm{C}$ and 0 to 8000 bar. Geochim. Cosmochim. Acta 56:2605-2617.

Foote, K. G., H. P. Knudsen, G. Vestnes, D. N. MacLennon, and E. J. Simmonds. 1987. Calibration of acoustic instruments for fish density estimation: a practical guide. ICES. Coop. Res. Rep. 144:1-57.

Greinert, J., Y. Artemov, V. Egorov, M. De Batist, and D. McGinnis. 2006. 1300-m-high rising bubbles from mud volcanoes at $2080 \mathrm{~m}$ in the Black Sea: Hydroacoustic characteristics and temporal variability. Earth Planet. Sci. Lett. 244:1-15.

- and B. Nutzel. 2004. Hydroacoustic experiments to establish a method for the determination of methane bubble fluxes at cold seeps. Geo. Mar. Lett. 24:75-85.

—, G. Rehder, Y. Artemov, and P. Gimpel. 2003. Visual and hydroacoustic investigations of gas bubbles detection and quantification of natural and man-made methane expulsions. Energy Explor. Exploit. 21:293-297.

Guet, S., S. Luther, and G. Ooms. 2005. Bubble shape and orientation determination with a four-point. Exp. Therm. Fluid Sci. 29:803-812.

Haberman, W. L., and R. K. Morton. 1954. An experimental study of bubbles moving in liquids. Proc. Am. Soc. Civ. Eng. 80:379-427.

Hornafius, J. S., D. Quigley, and B. P. Luyendyk. 1999. The world's most spectacular marine hydrocarbon seeps (Coal Oil Point, Santa Barbara Channel, California): Quantification of emissions. J. Geophys. Res. 104:2070320711. 
Horne, J. K., P. D. Walline, and J. M. Jech. 2000. Comparing acoustic model predictions to in situ backscatter measurements of fish with dual-chambered swimbladders. J. Fish Biol. 57:1105-1121.

Hovorka, R., M. J. Chappell, K. R. Godfrey, F. N. Madden, M. K. Rouse, and P. A. Soons. 1998. CODE: A deconvolution program implementing a regularization method of deconvolution constrained to non-negative values. Biopharm. Drug Dispos. 19:39-53.

Huttunen, J. T., T. Hammar, J. Alm, J. Silvola, and P. J. Martikainen. 2001. Greenhouse gases in non-oxygenated and artificially oxygenated eutrophied lakes during winter stratification. J. Environ. Qual. 30:387-394.

Jackson, D. R., K. L. Williams, T. F. Wever, C. T. Friedrichs, and L. D. Wright. 1998. Sonar evidence for methane ebullition in Eckernforde Bay. Cont. Shelf Res. 18:1893-1915.

Jakobsen, H. A., B. H. Sannaes, S. Grevskott, and H. F. Svendsen. 1997. Modelling of vertical bubble-driven flows. Ind. Eng. Chem. Res. 36:4052-4074.

Jamialahmadi, M., C. Branch, and H. Mullersteinhagen. 1994. Terminal bubble rise velocity in liquids. Trans. Int. Chem. Eng. 72A:119-122.

Johnson, B. D., and P. J. Wangersky. 1987. Microbubbles: stabilization by monolayers of adsorbed particles. J. Geophys. Res. 92:14641-14647.

Joyce, J., and P. W. Jewell. 2003. Physical controls on methane ebullition from reservoirs and lakes. Environ. Eng. Geoscience 9:167-178.

Kiene, R. P. 1991. Production and consumption of methane in aquatic systems, p. 111-146. In J. E. Rogers and W. B. Whitman [eds.], Microbial production and consumption of greenhouse gases: Methane, nitrogen oxides and halomethanes. Am. Soc. Microbiol.

Kieser, R., P. Reynisson, and T. J. Mulligan. 2005. Definition of signal-to-noise ratio and its critical role in split-beam measurements. ICES J. Mar. Sci. 62:123-130.

Leifer, I., and J. Boles. 2005. Measurement of marine hydrocarbon seep flow through fractured rock and unconsolidated sediment. Mar. Pet. Geol. 22:551-568.

— and K. Wilson. 2004. Quantified marine oil emissions with a video-monitored, oil seep-tent. Mar. Technol. Soc. J. 38:44-53.

—, G. De Leeuw, and L. H. Cohen. 2003. Optical measurement of bubbles: System design and application. J. Atmos. Ocean. Technol. 20:1317-1332.

- and A. G. Judd. 2002. Oceanic methane layers: the hydrocarbon seep bubble deposition hypothesis. Terr. Nova 14:417-424.

and R. K. Patro. 2002. The bubble mechanism for methane transport from the shallow sea bed to the surface: A review and sensitivity study. Cont. Shelf Res. 22:2409-2428.

, R. K. Patro, and P. Bowyer. 2000. A study on the temperature variation of rise velocity for large clean bubbles. J. Atmos. Ocean. Technol. 17:1392-1402.
Luther, S., J. Rensen, and S. Guet. 2004. Bubble aspect ratio and velocity measurement using a four-point fiber-optical probe. Exp. Fluids 36:326-333.

Lyons, A. P., M. E. Duncan, A. L. Anderson, and J. A. Hawkins. 1996. Predictions of the acoustic scattering response of freemethane bubbles in muddy sediments. J. Acoust. Soc. Am. 99:163-172.

Martens, C. S., and J. V. Klump. 1980. Biogeochemical cycling in an organic-rich coastal marine basin in methane-sediment exchange processes. Geochim. Cosmochim. Acta 44:471-490.

Mattson, M. D., and G. E. Likens. 1987. The effect of barometric pressure on methane ebullition rates. Eos 68:1691.

McGinnis, D. F., J. Greinert, Y. Artemov, S. E. Beaubien, and A. Wüest. 2006. Fate of rising methane bubbles in stratified waters: How much methane reaches the atmosphere? J. Geophys. Res. 111:C09007 doi: 10.1029/2005JC003183

—, A. Lorke, A. Wüest, A. Stockli, and J. C. Little. 2004. Interaction between a bubble plume and the near field in a stratified lake. Water Resour. Res. 40:W10206 doi: 10.1029/ 2004WR003038.

Morhac, M., and V. Matousek. 2005. Multidimensional FFT based positive definite gold deconvolution algorithm. J. Elec. Eng. 56:141-145.

Ostrovsky, I. 2003. Methane bubbles in Lake Kinneret: Quantification and temporal and spatial heterogeneity. Limnol. Oceanogr. 48:1030-1036.

— and P. Walline. 2001. Multiannual changes in the pelagic fish Acanthobrama terraesanctae in Lake Kinneret (Israel) in relation to food sources. Verh. Int. Verein. Limnol. 27:2090-2094.

— and Y. Z. Yacobi. 1999. Organic matter and pigments in surface sediments: possible mechanisms of their horizontal distributions in a stratified lake. Can. J. Fish. Aquat. Sci. 56:1001-1010.

Quigley, D. C., J. S. Hornafius, B. P. Luyendyk, R. D. Francis, J. Clark, and L. Washburn. 1999. Decrease in natural marine hydrocarbon seepage near Coal Oil Point, California, associated with offshore oil production. Geology 27:1047-1050.

Rowland, F. S. 1985. Methane and chlorocarbons in the earth's atmosphere. Orig. Life Evol. Biosph. 15:279-297.

Rudstam, L. G., and B. M. Johnson. 1992. Development, evaluation and transfer of new technology, p. 507-524. In J. F. Kitchell [ed.], Food web management: a case study of Lake Mendota. Springer-Verlag.

Saffman, P. G. 1956. On the rise of small air bubbles in water. J. Fluid Mech. 1:249-275.

Sam, A., C. O. Gomez, and J. A. Finch. 1996. Axial velocity profiles of single bubbles in water/frother solutions. Int. J. Miner. Process. 47:177-196.

Simmonds, E. J., and D. N. MacLennan. 2005. Fisheries acoustics: Theory and practice, 2nd ed. Blackwell.

St. Louis, V. L., C. A. Kelly, E. Duchemin, J. W. M. Rudd, and D. M. Rosenberg. 2000. Reservoir surfaces as sources of 
greenhouse gases to the atmosphere: a global estimate. BioScience 50:766-775.

Tassin, A. L., and D. E. Nikitopoulos. 1995. Nonintrusive measurements of bubble-size and velocity. Exp. Fluids 19:121-132.

Thorpe, S. A., P. Bowyer, and D. K. Woolf. 1992. Some factors affecting the size distributions of oceanic bubbles. J. Phys. Oceanogr. 22:382-389.

Urick, J. U. 1975. Principles of underwater sound. McGrawHill Book.

Vagle, S., and D. M. Farmer. 1992. The measurement of bubble-size distributions by acoustical backscatter. J. Atmos. Ocean. Technol. 9:630-644.

Vasconcelos, J. M. T., J. M. L. Rodrigues, S. C. P. Orvalho, S. S. Alves, R. L. Mendes, and A. Reis. 2003. Effect of contaminants on mass transfer coefficients in bubble column and airlift contactors. Chem. Eng. Sci. 58:1431-1440.

Walline, P. D., S. Pisanty, and T. Lindem. 1992. Acoustic assessment of the number of pelagic fish in Lake Kinneret, Israel. Hydrobiologia 231:153-163.
Walter, K. M., L. C. Smith, and F. S. Chapin. 2007. Methane bubbling from northern lakes: present and future contributions to the global methane budget. Phil. Trans. Roy. Soc. A 365:1657-1676 doi:1610.1098/rsta.2007.2036.

Werner, E., and R. Conrad. 2007. Sulfide and methane evolution in the hypolimnion of a subtropical lake: a three-year study. Biogeochemistry 82:67-76.

Weston, D. E. 1967. Sound propagation in the presence of bladder fish, p. 55-88. In V. M. Albers [ed.], Underwater acoustics. Plenum Press, New York.

Wüest, A., N. H. Brooks, and D. M. Imboden. 1992. Bubble plume modeling for lake restoration. Water Resour. Res. 28:3235-3250.

Yacobi, Y. Z., E. Ben-Bassat, D. Murad, and W. Eckert. 2000. Pigment variation in the photosynthetic sulfur bacterium Chlorobium phaeobactereoides from Lake Kinneret. Water Sci. Technol. 42:423-427.

Submitted 3 January 2007 Revised 24 October 2007

Accepted 26 October 2007 